\title{
A Convencionalização na Produção de Sementes na Agricultura Orgânica Brasileira ${ }^{1}$
}

\author{
Antonio Carlos Mendes Parra Filho², Luiz Antonio Cabello Norder ${ }^{3}$, \\ Pedro Jovchelevich ${ }^{4}$ e Sakae Kinjo ${ }^{5}$
}

Resumo: $\mathrm{O}$ crescimento da produção orgânica em muitos países está associado à adoção, pelos produtores, de práticas, tecnologias e formas de organização e comercialização encontradas na agricultura convencional. Isso levou a um debate internacional sobre a teoria da convencionalização da agricultura orgânica. Entretanto, o uso na agricultura orgânica de sementes e materiais de propagação contendo agroquímicos não tem sido suficientemente mencionado e estudado como parte deste processo. Diante disso, este artigo analisa a utilização de sementes convencionais como expressão da convencionalização de uma parcela da agricultura orgânica. Para tanto, apresenta uma caracterização do debate sobre convencionalização e da regulamentação brasileira sobre produção de sementes orgânicas; além disso, descreve e analisa iniciativas de empresas, agências governamentais e de organizações do terceiro setor visando a produção de sementes orgânicas para o mercado formal. A metodologia da pesquisa inclui a consulta a artigos científicos, análise de documentos e realização de entrevistas. Os resultados apontam para a complexidade e contradições da convencionalização na produção de sementes na agricultura orgânica e para a importância das organizações da agricultura familiar identificadas com o movimento agroecológico e dos agricultores vinculados aos movimentos "pioneiros" da agricultura ecológica na criação de novos canais de abastecimento de sementes orgânicas.

Palavras-chaves: Agricultura orgânica, convencionalização, produção de sementes, políticas públicas.

Abstract: The growth of organic production in many countries is associated with the adoption, by farmers, of practices, technologies and organizational and commercial categories present in conventional agriculture. This has led to an international debate on the theory of the conventionalization of organic agriculture. However, the use in organic agriculture of seeds and

1. Data de submissão: 7 de novembro de 2015. Data de aceite: 24 de fevereiro de 2018.

2. Centro de Pesquisa Mokiti Okada - CPMO/Fundação Mokiti Okada - MOA. Ipeúna-SP, Brasil. E-mail: acmendesparra@gmail.com

3. Universidade Federal de São Carlos (UFSCar), Araras-SP, Brasil E-mail: luiz.norder@gmail.com

4. Associação Brasileira de Agricultura Biodinâmica - ABD, Botucatu-SP, Brasil E-mail: pedro.jov@biodinamica.org.br

5. Centro de Pesquisa Mokiti Okada - CPMO/Fundação Mokiti Okada - MOA. Ipeúna-SP, Brasil. E-mail: sakae.kinjo@cpmo.org.br 
propagating material containing agrochemicals is not enough mentioned and studied as part of this process. Therefore, this article analyzes the use of conventional seeds as an expression of the conventionalization of a portion of organic agriculture. For that, it presents a characterization of the debate on conventionalization and the Brazilian regulation on organic seed production; in addition, it describes and analyzes initiatives of private companies, government agencies and third sector organizations aiming the production of organic seeds for the formal market. The methodology includes checking scientific articles, document analysis and interviews. The results of the research demonstrate the complexity and contradictions of the use of conventional seeds in organic agriculture and the importance of family farm organizations identified with the agroecological movement and farmers associated to the "pioneering" movements of organic farming in the creation of new supply channels for organic seeds.

Key-words: Organic agriculture, convencionalization, seed production, public policies.

Classificação JEL: Q13.

DOI: http://dx.doi.org/10.1590/1234-56781806-94790560402

\section{Introdução}

Nas últimas décadas, observou-se a expansão mundial da produção orgânica, realizada com base em diversificados processos de organização, regulamentação e institucionalização, que contaram com a participação de múltiplos atores sociais privados, governamentais e do terceiro setor. Alguns estudos evidenciam que o aumento da oferta de produtos orgânicos envolve empreendimentos familiares e não familiares. São encontrados modelos tecnológicos com maior especialização e a revalorização de tradicionais práticas de policultivo; do ponto de vista organizacional, há a comercialização em grande escala em grandes redes varejistas e o fortalecimento de novos sistemas de venda direta para os consumidores (LOCKIE e HALPIN, 2005; ALMEIDA e ABREU, 2009). Esta diversidade socioeconômica e tecnológica na agricultura orgânica tem sido, em grande medida, interpretada a partir dos conceitos de bifurcação e convencionalização da produção orgânica (BUCK et al., 1997; KRATOCHVIL e LEITNER, 2005; DARNHOFER et al., 2010; CONSTANCE et al., 2008; THORSØE e NOE, 2014).

Dentre as características da convencionalização na agricultura orgânica estão: a menor biodiversidade no ambiente de produção e no entorno, a substituição de processos ecológicos por insumos, a especialização e o aumento de área de produção por agricultor ou empresa, o uso de materiais genéticos não adequados aos sistemas orgânicos de produção, o trabalho assalariado e a comercialização através de grandes redes varejistas (DARNHOFER et al., 2010). Trata-se, enfim, da persistência de elementos da agricultura convencional nas dinâmicas produtiva e organizacional da agricultura orgânica. Todavia, o uso de sementes e mudas convencionais, contendo inclusive tratamento com agrotóxicos, pode ser apontado como um fator bastante relevante, mas ainda pouco pesquisado, no enfoque sobre a convencionalização da agricultura orgânica.

Diante disso, este artigo tem o objetivo de analisar o conceito de convencionalização e demonstrar sua relação com o uso de sementes e mudas na agricultura orgânica brasileira. Nas próximas duas seções será apresentada a metodologia da pesquisa e realizada uma análise do conceito de convencionalização, com destaque para o contexto brasileiro e para as sementes e materiais de propagação como um de seus componentes; em seguida, há um balanço sobre a trajetória da regulamentação brasileira sobre a produção de sementes e mudas na agricultura orgânica; na seção 5 serão identificadas e caracterizadas algumas importantes iniciativas de produção comercial de sementes orgânicas Brasil por organizações do setor privado, do setor público e do terceiro setor - e que ilustram não só o empenho de diferentes atores para superar os limites representados por esta expressão de convencionalização da agricultura orgânica, mas também seus limites, impasses e perspectivas; a seção 6 apresenta discussão 
e interpretação do tema e as considerações finais sistematizam e apontam para a importância do aprofundamento dos estudos sobre a convencionalização na produção de sementes na agricultura orgânica.

\section{Metodologia da pesquisa}

A metodologia inclui a consulta a publicações científicas que permitem delinear o conceito de convencionalização na agricultura orgânica e as características deste processo no Brasil, com foco na produção de sementes. Além disso, foi realizada uma análise da documentação e da regulamentação sobre o uso de sementes e mudas na agricultura orgânica brasileira, com destaque para sua relação com o conceito de convencionalização. Foram identificadas e selecionadas informações contidas em documentos oficiais, tais como Instruções Normativas e atas de reuniões da Comissão de Produção Orgânica de São Paulo em 2014 e 2015. Nas seções referentes às iniciativas de produção comercial de sementes orgânicas, além da consulta à bibliografia científica pertinente, foram analisados documentos divulgados pelas organizações de cada setor e realizadas entrevistas com profissionais representantes das instituições pesquisadas.

Assim, a pesquisa contém informações sobre as iniciativas de produção de sementes e mudas orgânicas realizadas por cinco empresas sementeiras, três de origem nacional e duas holandesas que atuam no território brasileiro. No setor público será abordada uma experiência de abrangência nacional realizada pela Empresa Brasileira de Pesquisa Agropecuária (Embrapa) e outras duas de abrangência estadual: uma pela Coordenadoria de Assistência Técnica Integral (Cati) e outra pela Empresa de Pesquisa Agropecuária do Estado do Rio de Janeiro (Pesagro-Rio). Em seguida, serão descritas algumas relevantes iniciativas na produção de sementes e mudas orgânicas conduzidas por três organizações do terceiro setor: a Rede de Sementes Agroecológicas Bionatur, a Associação Brasileira de Agricultura Biodinâmica (ABD) e o Centro de Pesquisas da Fundação Mokiti Okada (CPMO). As experiências aqui descritas foram selecionadas como referências ilustrativas para qualificar o objeto da pesquisa e não podem ser confundidas com a totalidade ou como uma amostragem do setor, nem reduz a importância de outras ações no mesmo sentido que já tenham sido realizadas.

\section{A convencionalização na agricultura orgânica}

O conceito de convencionalização da agricultura orgânica foi elaborado por Buck et al. (1997) a partir da análise da produção de commodities orgânicas na Califórnia - e refere-se à substituição de processos ecológicos, que até então vinham sendo utilizados pelos praticantes da agricultura orgânica, por máquinas, insumos, mercadorias e serviços externos, de forma similar à elevada industrialização e mercantilização presente na agricultura convencional (BUCK et al., 1997). Paralelamente, constatou-se que o aumento da produção orgânica ocorrera com base não apenas na agricultura familiar, mas também na agricultura empresarial. Teria ocorrido, portanto, uma bifurcação na agricultura orgânica, ou seja, uma segmentação entre a produção que, por um lado, vinha apresentando caraterísticas similares à produção convencional, com uso de insumos externos, trabalho assalariado, maior simplificação e especialização e, por outro, a produção fundamentada no trabalho familiar, detentora de maior artesanalidade e diversidade tecnológica e que vinha mantendo sistemas mais complexos e com maior agrobiodiversidade (CONSTANCE et al., 2008).

Buck et al. (1997) salientaram o aumento da participação de grandes empresas na cadeia de produção e a comercialização de produtos vegetais orgânicos de alto valor agregado. As empresas vinham atuando com base na especialização, aumento de escala e substituição de insumos, práticas apontadas como parte do processo de convencionalização, o que não impedia sua certificação como produção orgânica (LOCKIE e HALPIN, 2005; GUTHMAN, 2004; BUCK et al., 1997). Dessa forma, demonstrava-se que pelo menos parte da produção orgânica vinha reproduzindo práticas e lógicas da agricultura convencional - e desde então a "teoria da convencionalização" tornou-se tema de diversas publicações e eventos internacionais. Através da identificação e caracterização da agricultura ecológica empresarial e da agricultura ecológica familiar, Canuto (1998) apresentou, praticamente no mesmo período, uma análise bastante similar.

Em revisão bibliográfica sobre as práticas da agricultura orgânica "convencinonalizada", Darnhofer et al. (2010) identificaram algumas modificações nos sistemas produtivos da agricultura orgânica, vistas como 
problemáticas, na medida em que se distanciavam das dos princípios e práticas presentes entre os agricultores orgânicos "pioneiros". Nesta perspectiva, os agricultores orgânicos "pioneiros" passaram a ser reconhecidos como os "verdadeiros proponentes" da agricultura orgânica e suas práticas indicadas como referências. No entanto, nem todo rompimento em relação às práticas pioneiras pode ser tomado como uma convencionalização da produção orgânica.

Entre os potenciais indicadores de convencionalização estão: a baixa utilização de hortaliças e maior presença de cereais na rotação de culturas; rotações de culturas inadequadas; dependência de fertilizantes; intensa utilização de insumos fitossanitários; práticas que exigem insumos externos; pouca biodiversidade nas áreas cultivadas e no entorno das áreas cultivadas; medidas insuficientes para proteger o ecossistema da propriedade; uso de cultivares não adaptadas ao manejo orgânico. Assim, Darnhofer et al. (2010) apontam o uso de sementes e mudas convencionais como parte do processo de convencionalização da produção orgânica, mas este aspecto, no entanto, não havia sido objeto de estudos específicos mais aprofundados.

Kratochvil e Leitner (2005) identificaram as opiniões de aproximadamente 100 pesquisadores especialistas em produção orgânica sobre a "armadilha da convencionalização" durante a 8th Scientific Conference on Organic Agriculture, realizado na Hungria em março de 2005. Os participantes observaram diversos pontos críticos em relação às técnicas de produção utilizadas na agricultura orgânica, como a simplificação dos sistemas de produção, a utilização de insumos externos e a redução de integração da produção animal e vegetal. O aumento da área das propriedades e da escala de produção, visando manter a competitividade, também foi observado durante o crescimento da produção orgânica e que contribuía para explicar a redução no preço dos produtos orgânicos nas redes de varejo. Os autores também apontaram o aumento do número de empreendimentos caracterizados por um menor compromisso com os princípios até então preconizados pelos movimentos sociais ligados à agricultura orgânica (KRATOCHVIL e LEITNER, 2005).

Tal fenômeno foi identificado e analisado em diversos países. Thorsøe e Noe (2014) observaram diferentes formas de comercialização de produtos orgânicos na Dinamarca (varejistas, venda direta, delivery e lojas especializadas), que se relacionam com diferen- tes processos de produção. Ao pesquisarem produtores orgânicos de diversas especialidades (produtores de leite, carne, hortaliças e cereais), identificaram diversos sistemas de produção e estratégias de comercialização, bem como de controle de qualidade e de construção da confiança junto aos consumidores. Estas formas de produção e comercialização não eram necessariamente vinculadas à produção artesanal em pequena escala - e exploravam as possibilidades de parcerias com grandes redes de varejo. Também observaram a criação de nichos de mercados para alimentos de alta qualidade paralelos às grandes redes do comércio varejista (THORSØE e NOE, 2014).

Segundo Lockie e Halpin (2005), o crescimento na produção orgânica na Austrália ocorreu através de um aumento do número de pequenos e grandes agricultores, além do aumento da produção de produtores que já atuavam nesse segmento. Assim, demonstraram a necessidade de se ampliar o debate sobre a convencionalização para compreender sob quais situações este processo ocorre e em quais proporções. O crescimento da produção orgânica na indústria de carnes ocorreu predominantemente a partir da conversão de sistemas de produção convencionais, com maior dependência em relação a insumos externos. Já em setores como a horticultura, foi observada uma participação maior de pequenos agricultores, entre os quais os princípios da agricultura orgânica não representaram uma barreira para o aumento da escala de produção, considerada necessária para se manter a competitividade (LOCKIE e HALPIN, 2005).

Em muitos estudos, os empreendimentos familiares de produção orgânica aparecem ligados a princípios filosóficos, ideológicos, valores culturais não mensuráveis e participação em movimentos sociais, ao passo que, nos empreendimentos de produção orgânica em grande escala, as práticas agronômicas e comerciais mais sustentáveis foram substituídas por práticas mais próximas da agricultura convencional, como a monocultura e a venda indireta através de redes varejistas (LOCKIE e HALPIN, 2005). Na Alemanha, observou-se um pequeno número de grandes estabelecimentos de produção orgânica, o que, ao lado de um aumento da escala de produção entre novos agricultores orgânicos, indicava a existência de uma convencionalização incipiente. Mesmo assim, predominava largamente entre os agricultores uma forte orientação pró-sustentabilidade (BEST, 2006). 
No Brasil, as questões levantadas por meio dos conceitos de bifurcação e convencionalização podem ser identificadas através das contraposições política, social e tecnológica entre agricultura orgânica e o movimento agroecológico, que vem se intensificando nas últimas duas décadas. Para Assis e Romero (2002), a distinção entre agroecologia e agricultura orgânica parte da consideração de que uma fração dos agricultores orgânicos, especialmente os de maior capitalização, vinham estabelecendo uma produção "com base em tecnologias de produtos que não se afastam fundamentalmente na forma dos sistemas convencionais de produção" (ASSIS e ROMERO, 2002, p. 75). Nos anos seguintes, começaram a ser criadas algumas políticas públicas pontuais para a agricultura ecológica, através de projetos e programas governamentais, que não chegaram a romper com o predomínio da agricultura convencional e dos "monocultivos orgânicos, com foco na substituição de insumos" (CAPORAL e PETERSEN, 2012). Em 2012, foi criada a Política Nacional de Agroecologia e Produção Orgânica, na qual a dualidade manifesta-se em sua própria denominação (BRASIL, 2013, 2016).

A legislação brasileira, a partir de 2010, reconheceu três formas de certificação de produtos orgânicos: a certificação por auditoria de empresa especializada, a certificação por Organismo Participativo de Avaliação da Conformidade (OPAC) e a certificação por Organismo de Controle Social (OCS); estes dois últimos sistemas contam com um grande protagonismo das organizações de agricultores orgânicos na atividade de certificação. As certificações por auditoria e através de Opac recebem o selo do Sistema Brasileiro de Avaliação de Conformidade Orgânica (Sisorg) e permitem que os produtos sejam comercializados de forma indireta do produtor ao consumidor final. A certificação por OCS não permite o uso do selo do Sisorg, sendo válida apenas para agricultores familiares que realizam a venda direta e nos programas governamentais de aquisição de alimentos (ABREU et al., 2012; PEREZ-CASSARINO e FERREIRA, 2013; NIERDELE e ALMEIDA, 2013; ALMEIDA e ABREU, 2009).

Dalcin et al. (2013) mostram que os produtos orgânicos, a partir da virada do século, deixaram de se restringir aos mercados formados pelo público com maior identificação ideológica e passaram a ser adquiridos em grandes redes varejistas por consumidores com maior poder aquisitivo e preocupação voltada principalmente para a qualidade de sua alimentação, o que explica a expansão das vendas em grandes redes de supermercado e os investimentos nos pontos de venda, na diversificação da oferta e na apresentação dos produtos. Em estudo de caso sobre a Associação para o Desenvolvimento da Agroecologia (Aopa) do Paraná, Abreu et al. (2012) concluíram que os agricultores orgânicos que optaram pela venda indireta em circuitos longos em geral se especializaram em poucos produtos, comercializaram através de poucos canais de comercialização, recorreram à certificação por auditoria e enfatizaram o aumento de suas eficiências técnica e econômica (ABREU et al., 2012), o que reforçava as conclusões de Lockie e Halpin (2005) e outros autores sobre as práticas convencionais na agricultura orgânica.

Para Niederle e Almeida (2013), a convencionalização não ocorre somente na esfera de produção, mas na crescente atuação de empresas certificadoras e, em especial, na participação de redes varejistas na distribuição desses alimentos, que antes abasteciam circuitos mais curtos, locais e regionais. Os autores ressaltam que há, no Brasil, especificidades derivadas da legislação, o que permite a certificação participativa e o controle social como alternativas ao sistema de certificação por auditoria. Os sistemas de certificação participativos e de controle social são constituídos e executados por grupos de agricultores que levam em consideração as características locais e regionais, favorecem a troca de experiências entre os agricultores e a construção de canais alternativos de comercialização, como a venda direta aos consumidores através de feiras (PEREZCASSARINO e FERREIRA, 2013).

Almeida e Abreu (2009) caracterizaram os sistemas de produção de um grupo de agricultores familiares vinculados à Cooperativa dos Agropecuaristas Solidários de Itápolis/SP (Coagrosol) com foco na agrobiodiversidade, na ciclagem dos nutrientes e em aspectos socioeconômicos do processo de conversão agroecológica. Os autores definiram dois grupos de práticas, sendo agrupadas em agricultura de produtos (convencionalizadas) e práticas relacionadas à uma agricultura de processos (agroecológicas). Os resultados refletiram a grande diversidade de características dos agricultores familiares cooperados e evidenciaram diferentes paradigmas produtivos e ecológicos. Segundo os autores, "[...] praticamente a metade da amostra da pesquisa estava seguindo uma lógica antropocêntrica de substituição de insumos, enquanto 
a outra parcela era motivada por princípios ecológicos mais próximos de sistemas agroecológicos" (ALMEIDA e ABREU, 2009, p. 51).

Ainda assim, parte dos agricultores orgânicos familiares e pioneiros no Brasil permanece consumindo sementes convencionais, tratadas inclusive com agroquímicos (PARRA FILHO et al., 2015). Isso vem sendo observado e analisado em outros países. Pesquisa da Organic Seed Alliance mostrou que 31\% dos agricultores orgânicos norte-americanos entrevistados ampliaram, nos três anos anteriores, o percentual de uso de sementes orgânicas, $36 \%$ mantiveram o mesmo percentual, $6 \%$ o reduziram e $27 \%$ já vinham utilizando apenas sementes orgânicas (HUBBARD e ZYSTRO, 2016, p. 31).

Em estudo recente, MacGee e Alvarez (2016) retomam o debate internacional sobre a convencionalização e afirmam que a crescente dependência do setor convencional da agricultura orgânica em relação a fertilizantes e pesticidas orgânicos, ao reproduzir a contradição entre capitalismo e agricultura já indicada por Karl Marx, não apenas reduz seus benefícios ambientais e sociais, como também provoca um aumento na poluição da água em diversas regiões. Este fenômeno está relacionado à uma tendência, provavelmente global, apontada em diversos estudos recentes, de aumento na proporção da produção orgânica convencional no total da produção orgânica e de predominância, entre os agricultores orgânicos convencionais, de uma crescente intensificação no uso de recursos externos na produção, acompanhada de um discurso com uma ênfase voltada não mais para os princípios da agricultura orgânica ou da sustentabilidade, mas sobretudo para os problemas relacionados à fertilidade do solo, ao uso de fertilizantes, à poluição gerada na produção e à rentabilidade da atividade (DE WIT e VERHOOG, 2007).

A análise dos impasses na produção de sementes e materiais de propagação e sua relação com o debate sobre a convencionalização na agricultura orgânica não se resume a situações pontuais ou restrita a alguns poucos países. A Ifoam (International Federation of Organic Agriculture Moviments), que reúne mais de 800 organizações do movimento pela agricultura orgânica em mais de 100 países, chegou a elaborar, em 2011, um documento específico sobre o uso de sementes e materiais de propagação, no qual apontava, após ressaltar a importância das práticas tradicionais de conservação on-farm de recursos genéticos e dos circuitos infor- mais de sementes, os principais motivos relacionados à baixa utilização de sementes orgânicas no mercado formal do setor. A existência de uma demanda reduzida, dispersa e diversificada dificulta ou inviabiliza a organização da oferta pelas empresas sementeiras. Além disso, diante de uma oferta de sementes convencionais muito mais diversificada e com menor custo, os agricultores orgânicos optam pelas sementes convencionais visando um aumento na produção e na qualidade, bem como uma redução de riscos ou, ainda, o atendimento à padronização dos produtos destinados às grandes redes de varejo.

Diante isso, argumenta-se que, "se forem forçados a usar apenas materiais propagados organicamente, os agricultores perderão um grande número de variedades adaptadas" (IFOAM, 2011, p. 4). Paralelamente, reafirma-se que, mesmo sendo convencionais, as sementes não podem ser transgênicas, que as patentes e outras restrições legais devem ser refutadas e que deve ser conferida prioridade ao material genético que possa ser multiplicado pelos agricultores. Entre as recomendações apresentadas estão a de fortalecer os sistemas tradicionais e locais de circulação de sementes e a de, quando for o caso, usar as sementes convencionais em sistemas orgânicos. Uma plataforma foi, então, criada em 2015 para ampliar e disseminar o conhecimento sobre o acesso a sementes orgânicas entre as organizações de produtores. É interessante notar que, embora a Ifoam defenda a coexistência entre os mercados formal e informal de sementes, visando garantir a agrobiodiversidade, os exemplos mencionados no documento não deixam de remeter à noção de bifurcação: "supermercados... demandam produtos orgânicos certificados, uniformes e com vida longa de prateleira... Por outro lado, consumidores de mercados locais ou nichos de mercado estão mais interessados em variedades localmente adaptadas e com uma herança cultural" (IFOAM, 2011, p. 5).

\section{As sementes e mudas na agricultura orgânica brasileira}

A regulamentação da agricultura orgânica no Brasil foi resultado de cerca de 10 anos de debates realizados ao longo dos anos 1990 por diversas organizações. Durante a 9a Conferência Científica Internacional da Federação Internacional dos Movimentos de 
Agricultura Orgânica (Ifoam), ocorrida em São Paulo em 1992, foi apresentada a demanda por um modelo de certificação, exigida por países importadores (MEDAETS e FONSECA, 2005). Foram, então, elaboradas propostas para a regulamentação do setor, de forma participativa e com amplo debate com a sociedade.

A Lei da Agricultura Orgânica (Lei no $10.831 / 2003$ ) e seu decreto de regulamentação (Decreto n⿳o 6.323/2007) não mencionaram a utilização de sementes e mudas nesses sistemas de produção. A regulamentação sobre o uso das sementes na agricultura orgânica tem início com a Instrução Normativa (IN) nº 64/2008, que atualizou as disposições sobre os sistemas orgânicos de produções animal e vegetal. Foi fixado o prazo de cinco anos a partir de sua publicação para a utilização de sementes, mudas e materiais de propagação produzidos em sistemas orgânicos (BRASIL, 2008). No início de 2013, porém, o Ministério da Agricultura, Pecuária e Abastecimento (Mapa) constatou que ainda não havia oferta de sementes orgânicas suficiente no mercado formal voltada para o atendimento da demanda do setor produtivo, o que levou à proposição de modificações na regulamentação.

Após consulta pública organizada com auxílio da Câmara Temática de Agricultura Orgânica (CTAO) do Mapa, a Coordenação de Agroecologia (Coagre), setor do Mapa responsável pelas ações de desenvolvimento da agricultura orgânica, publicou a Nota Técnica no 60, de 13 de dezembro de 2013, definindo uma revogação do prazo apresentado anteriormente (COAGRE, 2013). Pouco depois, a IN no 17/2014 permitiu a utilização de sementes e mudas convencionais caso constatada a indisponibilidade de sementes e mudas orgânicas com características adequadas à situação ecológica da unidade de produção (BRASIL, 2014). Essa Instrução Normativa também determinou que, "[...] a partir de 2016, a Comissão de Produção Orgânica (CPOrg) de cada Unidade da Federação (UF) poderá produzir anualmente uma lista com as espécies e variedades que têm sementes orgânicas disponíveis no mercado [...]" (BRASIL, 2014: artigo 100o, parágrafo 3ํ). Além disso, proibiu o uso de organismos derivados da fusão de protoplasma e outras biotecnologias (Art. 101ํㅡ), além dos organismos geneticamente modificados (OGM) que já estavam proibidos anteriormente ${ }^{6}$.

6. A fusão de protoplasma é uma técnica de engenharia genética que possibilita transferir características entre espécies da mesma família botânica, que não seriam possíveis atra-
As Comissões de Produção Orgânica, organizadas por unidade federativa, foram instituídas pelo Decreto no 6.323/2007 (Lei da Agricultura Orgânica) e regulamentadas pela IN no 54/2008 com a finalidade de auxiliar o desenvolvimento da produção orgânica, sendo compostas por representantes de órgãos governamentais, da iniciativa privada e de organizações da sociedade civil que desenvolvem atividades relacionadas à produção orgânica. Há nas CPOrg grupos de trabalho (GT) que orientam e apoiam as tomadas de decisão. $\mathrm{O}$ Grupo de Trabalho de Sementes (GT Sementes) é composto por integrantes da CPOrg que desenvolvem atividades relacionadas à pesquisa e ao desenvolvimento de sementes orgânicas. Em reunião do GT Sementes da CPOrg/SP, em outubro de 2014, foi indicada a intenção de publicar não apenas a lista de sementes orgânicas disponíveis no mercado formal, mas também uma lista de sementes sem tratamento químico e outra com cultivares que não utilizaram a técnica de fusão de protoplasma em nenhuma etapa do seu ciclo de produção.

Outro impasse para o cumprimento desta norma é que as cultivares que utilizam a fusão de protoplasma não são identificadas. Na União Europeia, a lista de cultivares híbridas de brássicas que não utilizaram a técnica de fusão de protoplasma é publicada pelo Research Institute of Organic Agriculture (FiBL). Essas informações são fornecidas pelas empresas sementeiras - e as empresas que não enviam as informações solicitadas não são mencionadas na listagem oficial. Em reunião do GT Sementes, em 13 de outubro de 2014, foi mencionado que uma forma de se garantir o cumprimento da IN no 17/2014 seria permitir apenas a utilização de cultivares de polinização aberta (não híbridas) de brássicas; e solicitar que as empresas sementeiras informem quais cultivares são produzidas com o uso

vés de técnicas tradicionais de melhoramento. Essa técnica é utilizada com objetivo de produzir macho-esterilidade citoplasmática e, assim, baratear o processo de produção de híbridos de plantas da família das brássicas, como brócolis, couve-flor e repolho (BRASIL, 2014). Especialistas destacam que todas as etapas do melhoramento genético de plantas para a agricultura orgânica devem ser compatíveis com os princípios de agricultura orgânica - e concluíram que a agricultura orgânica é incompatível com a utilização de organismos geneticamente modificados, entre outros aspectos, por não permitirem que a cultivar seja utilizada para o desenvolvimento de novas cultivares (BUEREN et al., 2007). Da mesma forma, consideram que o uso de macho-esterilidade citoplasmática em programas de melhoramento impede que os agricultores utilizem o material genético (VELEMA, 2004). 
da fusão de protoplasma, diferente da "lista positiva" vigente na regulamentação europeia.

Vale lembrar que as normas técnicas da agricultura orgânicas já vinham exigindo a produção de sementes e mudas orgânicas em conformidade com a regulamentação relacionada às sementes e mudas em geral; além disso, complementarmente, na fase de campo, deveriam ser produzidas de acordo com a regulamentação específica aplicada à produção vegetal orgânica (BRASIL, 2011). A legislação de sementes vigente no Brasil (BRASIL, 2003, 2007) exige que a produção e comercialização de sementes e mudas no mercado formal, assim como as cultivares trabalhadas, estejam inscritas no Registro Nacional de Sementes e Mudas (Renasem) e no Registro Nacional de Cultivares (RNC). Os agricultores familiares e comunidades tradicionais mantiveram o direito de multiplicar e trocar suas sementes e a isenção de registro para as atividades de produção e comercialização de sementes crioulas.

\section{Produção comercial de sementes orgânicas no Brasil}

Nesta seção serão analisadas algumas inciativas de empresas sementeiras e organizações governamentais e do terceiro setor visando o abastecimento do mercado de sementes e mudas orgânicas. O estudo de caso abrange cinco empresas sementeiras, três agências governamentais e três organizações do terceiro setor.

\subsection{A atuação do setor privado}

Na produção de sementes comerciais predomina, de forma geral, a atuação de empresas de grande porte, de origem nacional e transnacional, que podem ser especializadas no segmento de sementes de grãos, de hortaliças ou em ambos. No Brasil, até 2015, houve algumas tentativas deste segmento visando ofertar sementes orgânicas no mercado formal. Serão aqui caracterizadas as iniciativas de cinco empresas sementeiras, sendo três delas de origem nacional e duas internacionais: as empresas nacionais Isla, Horticeres e Agristar e as transnacionais Bejo e Enza Zaden.

As empresas brasileiras Isla, Horticeres e Agristar já produziram sementes orgânicas de algumas poucas cultivares e as disponibilizaram de forma incipiente no mercado brasileiro a partir de 2003 (NASCIMENTO et $a l ., 2012)$. Entretanto, essas iniciativas não tiveram continuidade, por vários motivos. De acordo com informações fornecidas por funcionários indicados pelas próprias empresas analisadas, entre estes fatores está: a preferência dos agricultores orgânicos pelas sementes convencionais, de menor custo; a escassez de produtores orgânicos capacitados e dispostos a prestar os serviços de produção em parceria e, por fim, a dificuldade na certificação das unidades de beneficiamento, $o$ que aumenta os custos de produção. As empresas Bejo e Enza Zaden, ambas de origem holandesa, comercializam sementes orgânicas no mercado internacional, mas até 2015 não atuaram no segmento orgânico no Brasil.

A empresa Isla, fundada em 1955 em Candiota (RS), atua na produção de sementes de hortaliças, plantas ornamentais, ervas, temperos, frutas e árvores. Em 2001, lançou a primeira linha de sementes orgânicas, inicialmente com 16 cultivares importadas, com certificação europeia. Em 2003, conseguiu lançar cultivares orgânicas produzidas no Brasil e disponibilizar, nos anos seguintes, cerca de 50 cultivares, em parte importadas. Em 2014, interrompeu a comercialização de sementes orgânicas importadas de 30 cultivares de hortaliças, certificadas em seus países de origem e que necessitavam ser recertificadas através do Sistema Brasileiro de Avaliação de Conformidade Orgânica (SisOrg), administrado pelo Mapa. Segundo representante da empresa, entre os obstáculos para a continuidade e expansão da atividade estão: a) a reduzida demanda de sementes orgânicas por parte dos produtores; b) a flexibilidade na regulamentação sobre o uso de sementes orgânicas e c) a ausência de reconhecimento de certificações internacionais no Brasil. Por outro lado, a empresa disponibiliza toda linha de hortaliças, flores, ervas e temperos de sementes convencionais sem tratamento com fungicidas e inseticidas químicos vetados pela IN 46/2011.

A Horticeres Sementes, fundada em 1967 em Iguarapé (MG), atualmente presente em diversos países da América Latina, também atuou no ramo de sementes orgânicas. Em 2003, estimulada pelo crescimento da produção orgânica no Brasil, lançou sementes orgânicas de duas cultivares de alface produzidas e adaptadas ao clima brasileiro. Naquele período, havia sido publicada a primeira lei brasileira de produção orgânica. Porém, diante da insuficiente demanda e 
das dificuldades para localizar produtores orgânicos dispostos a realizar parcerias para a produção e multiplicação das sementes, a empresa passou a considerar inviável o desenvolvimento de uma linha de sementes orgânicas.

Também a Agristar, empresa nacional fundada em 1958, sediada em Petrópolis (RJ), ofertou sementes orgânicas no mercado brasileiro. A empresa atua em diversos segmentos e disponibiliza sementes de hortaliças, condimentos e plantas ornamentais. Suas cinco estações experimentais estão localizadas nos estados de Santa Catarina, São Paulo, Minas Gerais, Goiás e Rio Grande do Norte. A partir de 2002, comercializou sementes orgânicas de oito cultivares importadas da Itália. Segundo o proprietário da empresa, em entrevista para uma emissora de televisão em 2013, a empresa considerou que a demanda por sementes orgânicas era muito baixa e decidiu não dar continuidade a esta atividade.

A Bejo, estabelecida em Bragança Paulista (SP) desde 2001, comercializa sementes convencionais em todo o território nacional. Embora ofereça uma ampla diversidade de sementes orgânicas para comercialização na União Europeia e nos Estados Unidos, não ofertou sementes orgânicas no Brasil. Ao ser consultada por correio eletrônico, a gerência da empresa manifestou interesse em comercializar sementes orgânicas certificadas de acordo com as normas brasileiras e informou que desenvolve um Programa de Sementes Orgânicas que combina melhoramento genético em sistema de produção orgânico. Assim como as demais empresas, não encontrou condições favoráveis à comercialização de sementes orgânicas. Apesar de não ofertar sementes orgânicas, comercializa sementes sem tratamento com agrotóxicos.

Outra empresa holandesa que trabalha com uma ampla linha de sementes orgânicas no mercado internacional e que não importou sementes orgânicas para o Brasil foi a Enza Zaden. Segundo sua página na internet, como o Brasil representa o maior mercado na América do Sul, abriu uma filial em Holambra (SP) em 2015. A empresa incorporou em 1998 a Vitalis Seeds, especializada no melhoramento e na produção de sementes orgânicas de hortaliças comercializadas na União Europeia e América do Norte. O reconhecimento da certificação internacional foi considerado pela empresa como uma forte barreira para a comercialização de sementes orgânicas.

\subsection{A atuação do setor público}

Esta seção analisa uma experiência realizada pela Empresa Brasileira de Pesquisa Agropecuária (Embrapa) e duas iniciativas de agências estaduais: uma da Coordenadoria de Assistência Técnica Integral (Cati) e outra da Empresa de Pesquisa Agropecuária do Estado do Rio de Janeiro (Pesagro-Rio).

\subsubsection{A Embrapa Hortaliças (DF)}

A Empresa Brasileira de Pesquisa Agropecuária (Embrapa) conta com uma unidade especializada em hortaliças, na qual desenvolve cultivares adaptadas às condições brasileiras e oferece contribuição técnico-científica no segmento de sementes, inclusive com tecnologias para sementes orgânicas. Em 2013, a Embrapa Hortaliças, localizada em Gama (DF), foi contemplada em edital do Conselho Nacional de Desenvolvimento Científico e Tecnológico (CNPq) para a identificação, validação, avaliação, caracterização e conservação de variedades de sementes e criação de alternativas tecnológicas apropriadas à produção orgânica e de base agroecológica e aos bancos comunitários ou familiares de sementes.

Entre as ações desenvolvidas pela Embrapa Hortaliças estão o curso sobre Tecnologia de Produção de Sementes de Hortaliças, que não é focado na produção orgânica, e o seminário de Produção Orgânica de Sementes de Hortaliças. Até 2015, a única edição do seminário foi realizada em 2013, com os objetivos de discutir a produção orgânica de sementes de hortaliças como opção para geração de renda pelos agricultores, apresentar experiências de produção orgânica de sementes e a identificação de demandas para a pesquisa. Naquela ocasião, estiveram reunidos pesquisadores, técnicos e produtores da região interessados em aprimorar seus conhecimentos nesse segmento. $\mathrm{O}$ curso sobre Tecnologia de Produção de Sementes de Hortaliças acontece anualmente desde 2001 e cada edição é realizada em uma localidade escolhida a partir de estimativa de demanda. O público-alvo são estudantes, professores e profissionais das áreas de melhoramento genético, tecnologia de sementes e produção de hortaliças.

Vale destacar que, embora não haja oferta de sementes orgânicas para o mercado formal de forma direta pela Embrapa, a empresa forneceu sementes básicas 
para serem multiplicadas em sistema orgânico e comercializadas no mercado formal pela Rede de Sementes Agroecológicas Bionatur e ABD, que serão analisadas adiante. Além disso, alguns de seus pesquisadores participam de projetos voltados para o uso e conservação de sementes locais, tradicionais e crioulas junto a organizações de agricultores familiares e indígenas.

\subsubsection{Coordenadoria de Assistência Técnica Integral (Cati)}

Entre 2012 e 2013, técnicos da Cati participaram de cursos de capacitação em agricultura orgânica promovidos pela Agência Paulista de Tecnologias dos Agronegócios (Apta). No início de 2015, 36 dos 40 escritórios da Cati vinham realizando 66 projetos em fruticultura orgânica e 176 projetos com hortaliças orgânicas, com foco para tecnologias de produção (COMISSÃO DE PRODUÇÃO ORGÂNICA DE SÃO PAULO, 2015). Para garantir o abastecimento de sementes, mudas e matrizes de qualidade para o setor agropecuário, a Cati conta com o Departamento Técnico de Sementes, Mudas e Matrizes (DSMM), constituído por atividades de assistência técnica, pelo Centro de Produção de Sementes, com 15 Núcleos de Produção de Sementes, e por seis Núcleos de Produção de Mudas (SÃO PAULO, 1997). Dos 15 Núcleos de Produção de Sementes, 14 contam com uma equipe técnica de campo, laboratório de sementes e equipe de beneficiamento7. Uma "produção supletiva" visa suprir uma demanda específica que, por algum motivo, não é atendida por outros produtores de sementes para o mercado formal.

O DSMM da Cati mantém produção de sementes comerciais de aproximadamente 30 cultivares, divididas em 15 espécies. Em 2014, a Cati lançou sua primeira semente certificada orgânica de milho da variedade AL-Avaré para comercialização através de seus escritórios e casas de agricultura. Esta variedade, por ser de polinização aberta, permite que seja multiplicada pelos próprios agricultores familiares; ainda que não tenha sido desenvolvida especialmente para o sistema orgâ-

7. As atribuições gerais do Departamento de Sementes, Mudas e Matrizes (DSMM) são: "I - planejar e coordenar a produção e fornecimento de material básico para multiplicação vegetal; II - introduzir, testar, desenvolver, adaptar e difundir cultivares e tecnologias na área de sementes e mudas; III - produzir e fornecer sementes, mudas e outros materiais de propagação vegetativa, de forma supletiva; IV - manter bancos de germoplasma vegetal" (SÃO PAULO, 1997). nico, apresenta características desejáveis para estes sistemas. Para chegar a este resultado, a Cati contratou uma empresa de certificação por auditoria para a Unidade de Beneficiamento de Sementes (UBS) de Paraguaçu Paulista; o campo de multiplicação dessas sementes foi instalado em propriedade orgânica de agricultor parceiro do projeto, em Marília (SP).

Segundo o Diretor do DSMM, a comercialização de sementes orgânicas de milho não foi expressiva diante da regulamentação vigente, que permitia o uso de sementes convencionais, e do preço inicial de R\$ 18,00/kg. Os agricultores orgânicos preferiram adquirir, na própria Cati, sementes convencionais da mesma cultivar (AL-Avaré), pelo valor de R\$3,50/kg. A partir de janeiro de 2015, o preço das sementes orgânicas foi reduzido para $\mathrm{R} \$ 6,00 / \mathrm{kg}$. Mesmo assim, as vendas foram inexpressivas na safra 2014/2015. A Cati continuou buscando parcerias para a produção de sementes orgânicas de feijão, girassol, trigo e aveia. Embora incipiente, a produção de sementes orgânicas de forma suplementar representa a conquista de um espaço de discussão na SAA/SP e uma expectativa de se criar condições para aumentar a produção suplementar de sementes orgânicas.

A Apta integra o Conselho Nacional do Sistemas Estaduais de Pesquisa Agropecuária (Consepa) e a CPOrg/SP, inclusive com assento no GT Sementes; possui 19 Unidades de Pesquisa e Desenvolvimento (UPD) e, como parte da SAA/SP, atua junto a outras seis instituições: Instituto Agronômico (IAC), Instituto Biológico (IB), Instituto de Economia Agrícola (IEA), Instituto da Pesca (IP), Instituto de Tecnologia de Alimentos (ITAL) e Instituto de Zootecnia (IZ). As ações relacionadas à agricultura orgânica e à agroecologia são desenvolvidas conforme a vocação de cada região. A UPD de São Roque se dedica integralmente ao fortalecimento e desenvolvimento da agricultura de base ecológica na instituição. A UPD de Itararé, por exemplo, especializada no desenvolvimento de batatas, vinha buscando a certificação orgânica de parte de sua área para a produção de batata-semente orgânica e já havia desenvolvido ensaios de avaliação de desempenho de suas cultivares em cultivo orgânico.

\subsubsection{A Pesagro (RJ)}

A Empresa de Pesquisa Agropecuária do Estado do Rio de Janeiro (Pesagro-Rio), empresa vinculada 
à Secretaria de Estado de Agricultura, Pecuária, Pesca e Abastecimento e integrante do Sistema Nacional de Pesquisa Agropecuária (SNPA), do Consepa e da CPOrg/RJ, tem estações e campos experimentais, Laboratórios de Biologia Animal, de Controle de Qualidade e de Controle Biológico, no município de Niterói, onde está sua sede. Para viabilizar soluções tecnológicas e subsidiar políticas públicas para o desenvolvimento rural do estado do Rio de Janeiro (RJ), a Pesagro-Rio pesquisa e desenvolve sementes orgânicas de hortaliças, cereais e adubação verde, conforme as demandas da agricultura familiar.

A Pesagro-Rio compõe a Rede Estadual de Sementes Agroecológicas do Estado do Rio de Janeiro (Resa/RJ), junto à Universidade Federal Rural do Rio de Janeiro (UFRRJ), à Embrapa Agrobiologia, à Associação dos Agricultores Biológicos do Estado do Rio de Janeiro (Abio), à Articulação de Agroecologia do Rio de Janeiro (AARJ), ao Mapa, à Associação Brasileira de Agricultura Biodinâmica e ao Centro de Pesquisa da Fundação Mokiti Okada. Essa rede tem o objetivo de atender às demandas dos agricultores orgânicos do Rio de Janeiro por sementes de cultivares mais adaptadas às condições ecológicas das diversas regiões do estado através da formação de bancos comunitários de sementes. Destaca-se como característica diferencial da experiência da Resa/RJ, o envolvimento de entidades governamentais, institutos públicos de pesquisa, como a Pesagro-Rio, a Embrapa Agrobiologia, a Universidade Federal Rural do Rio de Janeiro (UFRRJ), em estreito laço com a Abio, organização do terceiro setor que realiza certificação participativa junto a mais de 360 produtores orgânicos e que completou 30 anos de atividades em 2015.

\subsection{A atuação do Terceiro Setor}

O terceiro setor é caracterizado por iniciativas privadas com origem na sociedade civil, composto por organizações não governamentais, fundações, institutos, associações, cooperativas e Organizações da Sociedade Civil de Interesse Público (Oscips) que oferecem serviços e produtos sem fins lucrativos. No Brasil, essas organizações assumiram um papel expressivo diante da retração do Estado nos anos 1990, que deixou lacunas a serem preenchidas para garantir os direitos sociais (OLIVEIRA e JÚNIOR, 2013). Foram escolhidas para este estudo as experiências da Rede de Sementes Agroecológicas Bionatur, da Associação Brasileira de Agricultura Biodinâmica (ABD) e do Centro de Pesquisa da Fundação Mokiti Okada (CPMO).

\subsubsection{A Rede de Sementes Agroecológicas Bionatur}

A Rede de Sementes Agroecológicas Bionatur, sediada em Candiota (RS) e representada juridicamente pela Cooperativa Agroecológica Nacional Terra e Vida (Conaterra), é composta por agricultores assentados produtores de sementes de diversas espécies, incluindo hortaliças, plantas ornamentais, forrageiras e grãos, em sistemas de produção orgânico para o mercado formal. Atualmente, a Bionatur constitui uma rede vinculada ao Movimento dos Trabalhadores Sem Terra (MST) e à Via Campesina e integra aproximadamente 160 famílias de agricultores que produzem anualmente em torno de 20 toneladas de sementes orgânicas de 88 variedades de diferentes espécies (SILVA et al., 2014). A legislação de sementes em vigor reconhece seis classes de sementes (genética, básica, certificada 1, certificada 2, S1 e S2). As sementes das classes S2 podem ser comercializadas, mas não podem ser utilizadas para a multiplicação com finalidade de comercialização de sementes no mercado formal.

A Bionatur buscou adquirir sementes básicas de cultivares disponíveis no mercado formal para multiplicação através dos respectivos mantenedores cadastrados no RNC. "Além do custo elevado destas sementes básicas ( 5 a 6 vezes superior ao das sementes comerciais), não conseguiram acesso a elas, pois os mantenedores afirmaram não dispor da quantidade necessária para o fornecimento e isso representou uma limitação recorrente à produção de sementes (LONDRES e SILVA et al., 2014). Essa situação foi manifestada ao Mapa pela Bionatur, com apoio da Associação Brasileira de Produtores de Sementes (Abrasem), através da Comissão de Sementes e Mudas do Rio Grande do Sul (CSM/RS). Diante disso, foi publicada a Nota Técnica no 025/2013 - CSM/DFIA/SDA/Mapa, de 15 de maio de 2013, que permitiu a comercialização de sementes de 36 espécies de hortaliças multiplicadas a partir de sementes da classe S2 até a safra de 2018/2019. Uma autorização similar já havia sido emitida anteriormente, em 2007, por meio da Informação CSM/DFIA/ SDA no 029/2007, para a multiplicação de sementes de 
hortaliças a partir da categoria S2, até a safra de 2011, por sugestão da CSM/RS.

Assim, verificou-se que, passados seis anos da autorização concedida em 2007, ainda não havia disponibilização das sementes orgânicas de hortaliças (CSM/ DFIA/SDA/MAPA, 2013). Mais uma vez, abriu-se uma exceção permitindo o uso de sementes S2 para produção comercial com a finalidade de viabilizar o atendimento dessas demandas, ainda que temporariamente, pois não enfrentou resistência dos mantenedores para comercializarem sementes de categorias acima da S2 (SILVA et al.; LONDRES, 2014). Mesmo sendo uma medida de caráter provisório, no entanto, as empresas interessadas deveriam solicitar o cadastro no RNC como mantenedores das cultivares que realizavam a multiplicação.

Segundo Silva et al. (2014), além da restrição no acesso às sementes básicas junto aos mantenedores, foram apontados outros obstáculos para a produção comercial de sementes orgânicas: a complexidade dos procedimentos e documentação atualmente exigidos pelo sistema formal e o custo inerente ao processo. Por estes motivos, a Bionatur solicitou ao Mapa a inscrição como mantenedora de algumas cultivares desenvolvidas pela Embrapa, com apoio da Embrapa Clima Temperado. No início de 2015, a Bionatur divulgou uma lista com 44 cultivares de 28 espécies para oferta no mercado de sementes orgânicas: abobrinha, alface, agrião, acelga, beterraba, cebola, cenoura, coentro, couve-chinesa, couve-manteiga, linhaça, melancia, melão, morango, moranga, mostarda, pimenta, quiabo, rúcula, tomate-cereja, salsa, feijão, milho, nabo-forrageiro, centeio, aveia, balsamina e zínia.

Com isso, a Bionatur tornou-se referência em produção comercial de sementes orgânicas. Essa cooperação entre a Embrapa e a Bionatur surgiu em resposta ao modelo hegemônico das empresas sementeiras que têm o foco na produção de sementes convencionais, muitas vezes de cultivares híbridas protegidas, em detrimento da produção de base agroecológica ou orgânica. Ao contrário, todas as cultivares produzidas e comercializadas pela Bionatur são variedades de polinização aberta. Dessa forma, os produtores interessados em produzir suas próprias sementes podem utilizar estes materiais para seleção e multiplicação. Embora a diversidade e escala de sementes produzidas e comercializadas pela Bionatur pudessem atender a um grupo relativamente pequeno de produtores, os resultados alcançados fortaleceram a perspectiva de constituição de um modelo eficaz de produção comercial, em bases solidárias, de sementes orgânicas por cooperativas de agricultores familiares.

\subsubsection{A Associação de Agricultura Biodinâmica}

A Associação Brasileira de Agricultura Biodinâmica (ABD), sediada no bairro Demétria, em Botucatu (SP), foi fundada em 1984 com a finalidade de difundir e promover a agricultura biodinâmica, preconizada pelo austríaco, filósofo e criador da Antroposofia, Rudolf Steiner (1861-1925), um profundo conhecedor da obra do alemão Johann Wolfgang von Goethe, que se dedicou aos estudos nas áreas de organização social, agricultura, arquitetura, medicina e pedagogia. Dentre as atividades desenvolvidas pela ABD está o serviço de consultoria, pesquisas, organização de cursos e eventos, publicações, preparados biodinâmicos e certificação participativa de produtos orgânicos e biodinâmicos. A Associação integra o grupo de trabalho de agrobiodiversidade da Articulação Nacional de Agroecologia (ANA) e comissões mistas compostas por organizações do governo e da sociedade civil, como a CPOrg/SP e, em âmbito federal, a Câmara Temática de Agricultura Orgânica (CTAO) do Mapa e a subcomissão temática de sementes da Comissão Nacional de Agroecologia e Produção Orgânica (CNAPO) (JOVCHELEVICH et al., 2014).

O trabalho de experimentação, melhoramento e produção de sementes da ABD teve início em meados da década de 2000, motivado pela percepção da importância do insumo semente na dinâmica da produção agrícola familiar, que ganha ainda mais relevância no contexto atual de oligopolização do mercado sementeiro no País (LONDRES, 2014). Para Jovchelevich et al. (2014), a restrição na disponibilidade de sementes comerciais leva os produtores de hortaliças à dependência do uso de agroquímicos, pois as cultivares híbridas ofertadas pelas empresas são condicionadas geneticamente a depender do uso intensivo de agroquímicos para que possam atingir os altos níveis de produtividade. Assim, a ABD passou a atuar em duas frentes estratégicas na produção de sementes: para o abastecimento de seus associados e para a comercialização no mercado de orgânicos (LONDRES, 2014).

Anualmente, desde 2011, a ABD promove a Festa das Sementes Orgânicas e Biodinâmicas do Sul de 
Minas, na qual ocorrem trocas de sementes e visitas técnicas nos campos de produção de sementes das associações participantes. A ABD co-organiza a Feira Estadual de Sementes Orgânicas do Estado de São Paulo, realizada anualmente desde 2010 em parceria com agricultores e organizações locais atuantes em agroecologia. Segundo participantes das festas, a troca de sementes permite que as variedades sejam multiplicadas e seu uso seja disseminado na região. Assim, as festas contribuem para processos sociais, como espaço para trocas de experiências e para a sensibilização e vêm registrando um número crescente de participantes (LONDRES, 2014).

A partir de 2012, a ABD passou a produzir sementes para comercialização no mercado formal, inicialmente com um trabalho junto a um grupo de 10 famílias agricultoras do assentamento Santo Dias, em Guapé (MG). Essas famílias receberam assessoria da ABD no processo de certificação participativa da produção orgânica, melhoramento participativo, produção de sementes de hortaliças para comercialização e recursos para a aquisição de peneiras e lonas para a limpeza e secagem de sementes (LONDRES, 2014). Ainda em 2012, ocorreu a primeira experiência de multiplicação de sementes orgânicas para comercialização, a partir de uma parceria com a rede Bionatur. Os agricultores de Guapé produziram $35 \mathrm{~kg}$ de sementes de alface, $8 \mathrm{~kg}$ de sementes de pimenta biquinho, $2 \mathrm{~kg}$ de sementes de berinjela e $1 \mathrm{~kg}$ de sementes de pimenta caiana em campos de produção registrados no Mapa pela Bionatur. Naquele período, a ABD não estava inscrita no Renasem e, por isso, as sementes foram comercializadas pela Bionatur (LONDRES, 2014).

A iniciativa da ABD de produção comercial de sementes para o mercado de orgânicos evidenciou a possibilidade de superação dos impasses na organização de um sistema de produção de sementes orgânicas. Segundo Londres (2014), o registro no RNC de uma variedade de abóbora desenvolvida a partir de melhoramento participativo foi considerado viável. A associação se cadastrou no Mapa como mantenedora dessa variedade, que ficou registrada em "domínio público", permitindo que qualquer produtor de sementes possa multiplicá-la sem a necessidade de autorização da associação. Para aumentar sua autonomia na produção de sementes básicas, a ABD tornou-se mantenedora de variedades de domínio público e de polinização aberta (não híbridas) (LONDRES, 2014). Em 2017, foram dis- ponibilizadas sementes orgânicas de três variedades de alface, uma de coentro, uma de milho, uma de pimenta e uma de tomate.

\subsubsection{A Fundação Mokiti Okada}

A Fundação Mokiti Okada (FMO), sediada em São Paulo (SP), é uma entidade jurídica de direito privado sem fins lucrativos e é considerada uma instituição de Utilidade Pública Federal. Foi fundada em 1971 com a missão de concretizar a filosofia de Mokiti Okada, a fim de criar o mundo ideal através de uma sociedade isenta de doenças, miséria e conflitos. Mokiti Okada (Japão, 1882-1955) foi filósofo e religioso, criador da Igreja Messiânica Mundial, no Japão, em 1935. A partir da observação de resultados satisfatórios em experimentações, passou a difundir os benefícios da agricultura natural como uma das colunas de sua filosofia. A agricultura natural preconizada por Mokiti Okada está baseada na observação e reprodução dos processos da natureza nos ambientes de produção agropecuária, visando resgatar a pureza do solo e dos alimentos, preservar a diversidade e o equilíbrio biológico e contribuir para a elevação da qualidade da vida humana.

Mokiti Okada considerou os agricultores como tesouros, uma vez que produzem os alimentos que sustentam a sociedade. Associando a qualidade dos alimentos à saúde humana, defendia uma prática agrícola sem uso de fertilizantes minerais e agrotóxicos e valorizava os alimentos de época e da região, considerando-os como mais ricos em energia vital. Segundo Demattê Filho (2014), a chave para o entendimento do pensamento de Mokiti Okada sobre a agricultura é que a natureza é capaz de suprir e suportar todas as formas de vida. Assim, uma questão primordial na agricultura natural é manter e promover a biodiversidade. Na concepção de Mokiti Okada (1992), a agricultura natural baseia-se principalmente em um solo sadio, capaz de produzir colheitas saudáveis pelo seu inerente poder natural. Mais que isso, o solo é dotado de espírito, vontade e sentimento. Assim, o solo não é apenas um suporte inerte para sustentação física das plantas. Essa concepção sugere que o pensamento e o sentimento do ser humano exercem grande influência no desenvolvimento das atividades produtivas (DEMATTÊ FILHO, 2014). Embora o modelo da agricultura natural e a filosofia de Mokiti Okada tenham sido originados no 
Japão, encontraram campo fértil para seu desenvolvimento no Brasil.

O Centro de Pesquisa Mokiti Okada (CPMO), localizado em Ipeúna (SP), é uma unidade da FMO que tem como objetivo pesquisar, desenvolver e difundir tecnologias para modelos de agricultura e pecuária sustentáveis, embasadas nos princípios da agricultura natural preconizada por Mokiti Okada. As áreas de atuação do CPMO são: Pesquisa e Desenvolvimento de Sementes, Manejo de Solo e Planta, Microbiologia Aplicada à Agricultura e Pecuária e Produção Animal. O CPMO também compõe a CPOrg/SP, o GT Sementes, a CTAO do Mapa e a Rede de Sementes Livres.

O setor de sementes visa a pesquisa e o desenvolvimento de sementes de olerícolas e grãos adaptados e selecionados dentro do cultivo no sistema de agricultura natural com o objetivo de atender praticantes de agricultura natural, agricultura orgânica e agricultores familiares. O CPMO obteve seu cadastramento no Mapa para realizar atividades de multiplicação, beneficiamento e comercialização de sementes e, assim, disponibilizar sementes orgânicas no mercado formal. As sementes que vinham sendo pesquisadas eram de variedades de polinização aberta de hortaliças, condimentos, flores, grãos e adubação verde, de forma que poderão ser utilizados pelos agricultores para multiplicação e uso de sementes próprias. Assim, utilizando sua marca Korin, passou a comercializar, inclusive pela internet, sementes orgânicas de quatro variedades de alface, uma de brócolis, uma de coentro e uma de tomate.

\section{Uma convencionalização ampliada}

A análise apresentada acima pode contribuir para um aprofundamento da discussão sobre o conceito de convencionalização da agricultura orgânica e suas características no Brasil. Vimos que o conceito de convencialização designa a reprodução na agricultura orgânica, com amparo da regulamentação específica do setor, de práticas, produtos e processos característicos da agricultura convencional, tais como a especialização em monocultivos em grande escala, a dependência em relação ao trabalho assalariado, o consumo de fertilizantes de origem industrial e a comercialização através de grandes redes varejistas. A produção e consumo de sementes pode ser mencionada como um compo- nente relevante no debate sobre a convencionalização da agricultura orgânica.

Vale destacar que, a princípio, é possível identificar a lógica da convencionalização na produção de sementes mesmo quando produzidas em sistemas orgânicos, ou seja, nos casos em que suas técnicas e formas de organização social apresentem similaridade com os sistemas convencionais. Assim, a existência de um mercado de sementes orgânicas, por si só, não representa, necessariamente, uma ruptura com a convencionalização, mas justamente o seu estabelecimento, caso haja, entre outras características, o predomínio de grandes empresas sementeiras. Entretanto, as contradições e impasses na produção de sementes, como mostra o caso brasileiro, revela não apenas uma similaridade com os sistemas convencionais, mas o uso, nas sementes, de substâncias que a própria regulamentação proíbe em seu processo produtivo. Com isso, o uso de sementes tratadas com agroquímicos pode ser interpretada como uma convencionalização ampliada e, inclusive, em termos normativos, contraditória. Os impasses e contradições da produção orgânica convencional, no que se refere ao suprimento de sementes no mercado formal, apresentam grande magnitude. Não se pode descartar, no debate público sobre a regulamentação do setor, a possibilidade de se exigir pelo menos o uso de sementes isentas de determinados tratamentos com agrotóxicos e de técnicas como a fusão de protoplasmas.

Por outro lado, constata-se que as organizações sem fins lucrativos ligadas aos agricultores "pioneiros" e à agricultura familiar vêm obtendo, no polo oposto ao da convencionalização, os mais expressivos êxitos, ainda que local e regionalmente, em produzir e ofertar sementes orgânicas através de um mercado solidário, não empresarial, não convencional, com sementes orgânicas que podem ser multiplicadas pelos agricultores. Paralelamente aos circuitos informais presentes nas organizações da agricultura familiar, tais iniciativas constituem, portanto, redes de conservação, distribuição e uso de sementes orgânicas locais, frequentemente identificadas com a agroecologia. Isso aponta para um acirramento da bifurcação. Mesmo assim, uma parcela dos agricultores orgânicos familiares e/ou "pioneiros" continua a usar, ainda que parcialmente, sementes oriundas do setor convencional, tratadas com agroquímicos. Isso mostra que a separação entre as duas vertentes da bifurcação, no que se refere ao uso de sementes, não pode ser tomada como algo absoluto ou estanque. 


\section{Considerações finais}

O processo de convencionalização na agricultura orgânica pode ser analisado em suas diferentes dimensões e intensidades. Apesar de sua relevância, não há na literatura específica análises mais aprofundadas sobre a complexidade, os impasses e contradições no uso de sementes e materiais de propagação e sua importância para o debate sobre convencionalização na produção orgânica. Vimos que no processo de regulamentação do uso de sementes e mudas na produção orgânica brasileira há uma espécie de círculo vicioso, no qual a ausência de oferta de sementes orgânicas no mercado formal é apresentada como justificativa para a permissão temporária do uso de sementes convencionais, inclusive tratadas quimicamente; mas isso impede a geração da demanda e, simultaneamente, a criação de um setor de produção comercial de sementes orgânicas. O setor privado de produção de sementes, que se estabeleceu conforme a lógica da agricultura convencional, também buscou atuar no setor de orgânicos, mas não encontrou condições favoráveis para realizar a oferta. Com isso, o prazo para a transição previsto na regulamentação foi derrogado - e o setor privado, que também tentou, sem êxito, comercializar sementes orgânicas importadas, deixou de atuar nesse segmento por considerar a demanda inexistente ou insuficiente.

Há algumas iniciativas relevantes, mas ainda incipientes, conduzidas por diferentes agências governamentais visando o fortalecimento na produção de sementes orgânicas. Destaca-se o apoio às ações das organizações da agricultura familiar na organização do mercado informal de sementes orgânicas e agroecológicas. Nota-se que os maiores avanços foram observados no terceiro setor, justamente aquele vinculado aos agricultores considerados "pioneiros" do movimento orgânico, que disponibilizou sementes de polinização aberta em circuitos de economia solidária com expressivo número de variedades adaptadas ao manejo orgânico. Tais experiências protagonizadas pelos movimentos sociais contribuíram para a superação, ainda que parcial e regionalmente, de alguns dos impasses enfrentados pelo mercado formal de sementes orgânicas. Essas iniciativas situam-se no ramo da bifurcação que contesta abertamente a convencionalização na agricultura orgânica - e que vêm sendo crescentemente identificadas com a agroecologia e com o movimento agroecológico.
Na regulamentação e no funcionamento da agricultura orgânica brasileira podem ser destacadas pelo menos duas características: uma é a certificação participativa realizada pelas organizações dos próprios agricultores herdeiros do ramo "pioneiro", que vêm, há quase duas décadas, se mobilizando enquanto movimento agroecológico; a segunda é que o setor convencional da agricultura orgânica conta com uma regulamentação que prorroga sucessivamente a manutenção do contraditório círculo vicioso representado pela produção de sementes tratadas com agrotóxicos. Este cenário sugere a importância de novos estudos sobre o tema, dentre os quais podem ser mencionados: a realização de comparações internacionais, estudos de caso sobre o uso de sementes entre agricultores familiares e nos sistemas participativos de garantia, as possibilidades de redução de custo no mercado formal, o funcionamento dos circuitos solidários de fornecimento de sementes orgânicas e os investimentos em pesquisa, tecnologia e inovação.

\section{Referências}

ABREU, L. S. et al. Relações entre agricultura orgânica e agroecologia: desafios atuais em torno dos princípios da agroecologia. Revista Desenvolvimento e Meio Ambiente, v. 26, p. 143-160, 2012.

ALMEIDA, G. e ABREU, L. S. Estratégias produtivas e aplicação de princípios da Agroecologia. Revista de Economia Agrícola, v. 56, n. 1, p. 37-53, 2009.

ASSIS, R. L. e ROMERO, A. R. Agroecologia e agricultura orgânica: controvérsias e tendências. Desenvolvimento $e$ meio ambiente, Curitiba, n. 6, p. 67-80, 2002.

BELLON, S. et al. The relationships between organic farming and agroecology. In: 3. ISOFAR Scientific Conference at the 17. IFOAM Organic World Congress, Gyeonggi Paldang, KOR. ISOFAR-International Society of Organic Agriculture Research, 2011.

BEST,H. Organic agriculture and the conventionalization hypothesis: a case study from West Germany. Agriculture and human values, v. 25, p. 95-106, 2008.

BRASIL. Lei no 10.831, de 23 de dezembro de 2003. Dispõe sobre a agricultura orgânica e dá outras providências. Diário Oficial [da] República Federativa do Brasil, Brasília-DF, 24 dez. 2003.

. Decreto no 6.323, de 27 de dezembro de 2007. Regulamenta a Lei no 10.831, de 23 de dezembro 
de 2003, que dispõe sobre a agricultura orgânica, e dá outras providências. Diário Oficial [da] República Federativa do Brasil, Brasília-DF, 28 dez. 2007.

Ministério da Agricultura, Pecuária e Abastecimento. Instrução Normativa n. 54 de 22 de outubro de 2008. Regulamenta a estrutura, composição e atribuições das Comissões da Produção Orgânica. Diário Oficial [da] República Federativa do Brasil. Brasília, 23 out. 2008a. Seção 1, p. 36-37.

Ministério da Agricultura, Pecuária e Abastecimento. Instrução Normativa no 64, de 18 de dez. 2008. Regulamenta a Produção Animal e Vegetal na Agricultura Orgânica. Diário Oficial [da] República Federativa do Brasil. Brasília, 19 dez. 2008b. Seção 1, p. 21-26.

Ministério da Agricultura, Pecuária e Abastecimento. Instrução Normativa no 17 , de 18 de jun. 2014. Regulamento Técnico para os Sistemas Orgânicos de Produção Animal e Vegetal. Diário Oficial [da] República Federativa do Brasil, Brasília-DF, 20 jun. 2014. Seção 1, p. 32-36.

Plano Nacional de Agroecologia e Produção Orgânica - PLANAPO 2016-2019. Brasília: Ministério do Desenvolvimento Agrário, 2016.

BUCK, D., GETZ, C. e GUTHMAN, J. From farm to table: the organic vegetable commodity chain of Northern California. Sociologia Ruralis, v. 37, n. 1, p. 3-20, 1997.

BUEREN, E. T. L. Agriculture requires process rather than product evaluation of novel breeding techniques. NJAS Wageningen Journal of Life Sciences, v. 54, n. 4, p. 401-412, 2007.

BUIATTI, M. et al. The law of the seed. Firenzi: Navdanya International, 2013. $40 \mathrm{p}$.

CANUTO, J. C. Agricultura ecológica e sustentabilidade sócio-ambiental. Raízes, v. 16, p. 13-24, 1998.

CAPORAL, F. R. e PETERSEN, P. Agroecologia e políticas públicas na América Latina: o caso do Brasil. Agroecología, Murcia, n. 6, p. 63-74, 2012.

COAGRE. Nota Técnica no 60, Brasília: Coordenação de Agroecologia, Ministério da Agricultura, Pecuária e Abastecimento, 2013.

COMISSÃO DE PRODUÇÂO ORGÂNICA DE SÃO PAULO. Ata da reunião realizada no dia 23 de março de 2015. São Paulo: Instituto Biológico, 2015.

CONSTANCE, D. H., CHOI, J. Y. e LYKE-HOGLAND, H. Conventionalization, bifurcation, and quality of life: Certified and non-certified organic farmers in Texas. Southern Rural Sociology, v. 23, n. 1, p. 208-234, 2008.

DALCIN, D. et al. Organic products in Brazil: from an ideological orientation to a market choice. British Food Journal, v. 116, n. 12, p. 1998-2015, 2013.

DARNHOFER, I. et al. Conventionalisation of organic farming practices: from structural criteria towards an assessment based on organic principles. A review. Agronomy for Sustainable Development, v. 30, n. 1, p. 67-81, 2010.

DEMATTÊ FILHO, L. C. Sistema agroalimentar da avicultura fundada em princípios da Agricultura Natural: multifuncionalidade, desenvolvimento territorial e sustentabilidade. Tese de Doutorado. Universidade de São Paulo. Escola Superior de Agricultura Luiz de Queiroz. Centro de Energia Nuclear na Agricultura, Piracicaba, 2014. 251 p.

DE WIT, J. e VERHOOG, H. Organic Values and the conventionalization of organic agriculture. NJAS Wageningen Journal of Life Sciences, v. 54, p. 449-462, 2007.

GLIESSMAN, S. Agroecologia: processos ecológicos em agricultura sustentável. 4. ed. Porto Alegre: Ed. Universidade/UFRGS, 2009.

GUTHMAN, J. The trouble with 'organic lite'in California: a rejoinder to the 'conventionalisation' debate. Sociologia Ruralis, v. 44, n. 3, p. 301-316, 2004.

HUBBARD, K. e ZYSTRO, J. State of organic seed, 2016. Port Townsend: Organic Seed Alliance, 2016.

IFOAM. The use of organic seed and plant propagation material in organic agriculture. Position Paper. Bonn: IFOAM, 2011.

JOVCHELEVICH, P., MOREIRA, V. e LONDRES, F. Rede de sementes biodinâmicas: reconstruindo a autonomia perdida na produção de hortaliças. Revista Agriculturas: experiências em agroecologia, Rio de Janeiro, p. 38-44, 20 jun. 2014.

KRATOCHVIL, R. e LEITNER, H. The trap of conventionalisation: organic farming between vision and reality. Paper for Working Group, v. 5, 16 p., 2005.

LOCKIE, S. e HALPIN, D. The 'conventionalisation' thesis reconsidered: structural and ideological transformation of Australian organic agriculture. Sociologia Ruralis, v. 45, n. 4, p. 284-307, 2005.

LONDRES, F. A associação biodinâmica e o desafio da produção de sementes de hortaliças. Rio de Janeiro: ANA, ABD, AS-PTA, 2014. 
MEDAETS, J. P. e FONSECA, M. F. Produção orgânica: regulamentação nacional e internacional. Brasília: Ministério do Desenvolvimento Agrário: NEAD, 2005.

NASCIMENTO, W. M., VIDAL, M. C. e RESENDE, F. V. Produção de sementes de hortaliças em sistema orgânico. In: Embrapa Hortaliças (Ed.). Curso sobre Tecnologia de produção de sementes de hortaliças. Mossoró; Brasília: Embrapa, 2012.

NIEDERLE, P. A. e ALMEIDA, L. A nova arquitetura dos mercados para produtos orgânicos: o debate da convencionalização. In: NIEDERLE, P. A., ALMEIDA, L. e VEZANNI, F. M. (Orgs.). Agroecologia: práticas, mercados e políticas para uma nova agricultura. Curitiba: Kairós, 2013, p. 23-47.

PARRA FILHO, A. C. M. Sementes orgânicas: regulamentação, políticas públicas, produção comerciale uso de sementes locais em estabelecimentos certificados. Dissertação de Mestrado. Universidade Federal de São Carlos. Programa de Pós-Graduação em Agroecologia e Desenvolvimento Rural. Araras, 2015. 108 p.

.et al. Uso de sementes por agricultores orgânicos do Estado de São Paulo: comparação entre certificação por auditoria e sistema participativo de garantia. Cadernos de Agroecologia, v. 10, n. 3, p. 1-12, 2015.

PEREZ-CASSARINO, J. e FERREIRA, A. D. D. Agroecologia, construção social de mercados e a constituição de sistemas agroalimentares alternativos: uma leitura a partir da Rede Ecovida de Agroecologia. In: NIEDERLE, P., ALMEIDA, L. e VEZZANI, F. M. (Orgs.). Agroecologia: práticas, mercados e políticas para uma nova agricultura. Curitiba: Kairós, 2013, p. 171-214.

OKADA, M. A outra face da doença: a saúde revelada por Deus. Tokyi: MOA SHOJI, 1992.

OLIVEIRA, J. R. e SILVA JUNIOR, S. G. Atuação da Organizações não governamentais - relação com o perfil dos atores e gestores. Simpósio de Excelência em Gestão e Tecnologia. Resende/RJ: Associação Educacional Dom Bosco, 2013.

SILVA, P. M. et al. Rede de Sementes Agroecológicas Bionatur: uma trajetória de luta e superação. Revista Agriculturas, v. 11, n. 1, p. 33-37, 2014.

THORSØE, M. H. e NOE, E. Conventionalization or diversification? Development in the Danish organic production sector following market expansion. The 11th European IFSA Symposium, Humboldt University, Berlin, 1-4, 2014.

VELEMA, J. Challenges and opportunities in organic seed production. In: Processing of the First World Conference on Organic Seed: challenges and opportunities for organic agriculture and seed industry. Roma: IFOAM/FAO/ISF, 2004.

Todo o conteúdo deste periódico, exceto onde estiver identificado, está licenciado sob uma Licença Creative Commons (cc by 4.0). 
